\title{
Somatoform complaints in middle childhood A developmental path-analysis
}

\author{
Christina Vesterling ${ }^{1}\left(\mathbb{D} \cdot\right.$ Ute Koglin $^{1}$
}

Accepted: 12 April 2021 / Published online: 21 April 2021

(C) The Author(s) 2021

\begin{abstract}
Repeatedly occurring somatoform complaints often cause disruptions in children's daily life, both in family and school settings. Associated with these complaints, there is an increased demand for medical help in the affected children. Despite the frequent occurrence of somatoform complaints in childhood, only a small number of studies have focused on this subject, and the development and maintenance of somatoform complaints have not sufficiently explained to date. Previous research suggests that many different factors are involved, including insecure attachment, a lack of emotion regulation (ER) strategies, and psychiatric behavior problems. The aim of this study is to examine possible pathways describing the interplay of aforementioned factors, in order to contribute to a deeper understanding of the underlying mechanisms. A nonexperimental cross-sectional study was conducted. Questionnaires were completed by 221 children (female $n=115 ; M_{\mathrm{age}}=9.70$ years, $\mathrm{SD}_{\text {age }}=.56$ ) reporting on their attachment and ER strategies, and their parents reported on the behavior problems and somatoform complaints. Path analysis revealed a good model fit $\left(\mathrm{X}^{2}=\mathrm{p} .798, \mathrm{X}^{2} / \mathrm{df}=.415, \mathrm{NFI}=.994, \mathrm{CFI}=1.000\right.$, RMSEA $\left.=.000\right)$. Results revealed that attachment anxiety predicted maladaptive ER strategies, and attachment avoidance predicted emotion control. In turn significant paths were found between ER strategies, behavior problems, and somatoform complaints. This study provides a first insight into the underlying mechanisms describing the occurrence of somatoform complaints. Results revealed two developmental pathways, based on attachment quality and mediated through different emotion regulation strategies.

Clinical Trial Registration: The project "Impact factors and conditions of somatoform symptoms in childhood within familial and school contexts" is listed in the German Clinical Trails Register (DRKS-ID: DRKS00012444) and the WHO International Clinical Trials Registry Platform.
\end{abstract}

Keywords Somatoform complaints $\cdot$ Attachment $\cdot$ Emotion regulation $\cdot$ Behavior problems $\cdot$ Middle childhood

\section{Introduction}

Somatoform complaints, like headaches, stomachaches or dizziness, are often the reason for social withdrawal and decreased activeness in children. Repeatedly occurring symptoms can cause disruptions in children's daily life, both in family and school settings. These often leads to uncertainty in parents, which in turn increases the symptoms and might support school avoidance behavior (Bernstein et al., 1997) and an increase seeking medical help for somatoform complaints

Christina Vesterling

christina.vesterling@uni-oldenburg.de

1 Department of Special Needs Education and Rehabilitation, Carl von Ossietzky University of Oldenburg, Ammerländer Heerstr. 114-118, 26129 Oldenburg, Germany is very common in childhood (Kelly et al., 2010). Whilst the psychosomatic illness patterns in childhood seldom fulfil the complete criteria set of a somatoform disorder, the impacts of children's health and well-being is frequently so strong that they are relevant to pediatric or psychotherapeutic treatments. Somatoform complaints are frequently found in school-aged children. Kelly et al. (2010) reported prevalence ranges of $17.8 \%$ to $43.8 \%$ for girls and $10.7 \%$ to $42.3 \%$ for boys. Due to an increase in cognitive abilities, school-age children are able to give a self-report on their emotional state, regulationsor coping strategies, and/or their wellbeing. Thus, from a developmental perspective this age group is of special interest in examining somatoform complaints.

Despite the high prevalence of somatoform complaints in middle childhood, the factors influencing the development and continuous occurrence, could not be explained sufficiently to date. Based on previous literature, an association between behavior problems, lack of emotion regulation 
strategies (ER strategies) or mother-child attachment and somatoform complaints have been suspected and examined in previous research (Koechlin et al., 2018; Vesterling \& Koglin, 2020).

\section{Somatoform Complaints}

Somatoform symptoms are operationalized as physical illness symptoms without a medical explanation, under 'Somatoform Disorders (SD)' in the DSM-III and DSM-IV (American Psychiatric Association, 1980, 1987, 1994, 2000) and in ICD 10 (Dilling, 2011). However, in the DSM-5 (American Psychiatric Association, 2013) it was no longer relevant if a physical symptom can or cannot be explained medically. According to the 'Somatic Symptom Disorder (SSD)' (Criterion A) in the DSM-5, 'one or more physical symptoms, causing disruption in daily life over a period of at least six months (Criterion C) and an emotional evaluation of these symptoms (Criterion-B) are required for the recognition of this psychiatric disorder. Differences between diagnostic criteria in the DSM editions have been described elsewhere (American Psychiatric Association, 1980, 1987, 1994, 2000, 2013; Dilling, 2011; van Dessel et al., 2016). In the current study, we only focus on somatoform complaints and not on the complete 'Somatic Symptom Disorder (SSD)'; hence, we forego the B-Criterion.

\section{Attachment}

Based on the theoretical background of attachment theory, infant attachment is described as a dynamic process in child development, highlighting the primary need for comfort and protection by a caregiver in stressful situations (Ainsworth et al., 1978; Bowlby, 1969/1982, 1973, 1980, 1988; Bretherton, 1987; Main et al., 1985). To get attention and support by a caregiver, infants show attachment behavior like crying, clinging or screaming. Depending on the caregiver's individual sensitivity, caregiving behavior will be shown and in turn interaction experiences with the infant will be made (Ainsworth et al., 1978; Bowlby, 1969/1982, 1980, 1988; Main et al., 1985). Different kinds of interaction experiences result in different internal working models in children, which are fundamentally important for their development, especially the development of ER strategies (Cassidy, 1994). Securely attached children have experienced reliable and efficient support, which results in a high self-efficacy and certainty that in the end all will turn out well (Ainsworth et al., 1978; Bowlby, 1969/1982; 1980, 1988; Cassidy, 1994; Main et al., 1985). In contrast, insecurely attached children are often left on their own overwhelmed with their emotions. As they cannot rely on the caregiver's support, they try to regulate themselves, thereby developing ineffective and unhealthy ER strategies (Ainsworth et al., 1978; Bowlby, 1969/1982; Main et al.,
1985). This can foster the development of psychopathological outcomes (Bowlby, 1980). More precisely, children with an avoidance attachment style have made the experience that the caregiver shows a rejective response to the infant's attachment behavior. To prevent this painful rejection, children try to avoid requesting for help. Instead, they try to regulate themselves by negating 'negative' (e.g. anger, sadness or anxiety) emotions and using ER strategies like emotion control or suppression, which in their experience have been effective and useful (Cassidy, 1994; Kotler et al., 1994; Mikulincer \& Shaver, 2007). In contrast, children with an anxiety attachment style tend to catastrophize their emotions in order to be heard and supported by their caregivers (Brumariu, 2015; Cassidy, 1994). If they do not succeed, their self-efficacy beliefs will be reduced and feelings of helplessness increased. This leads to unhealthy attempts to adapt by using maladaptive internal ER strategies like 'giving up', 'self-blame', 'selfdevaluation', or 'rumination' (Shaver \& Mikulincer, 2002). However, based on the theoretical background of attachment theory (Ainsworth et al., 1978; Bowlby, 1969/1982, 1980, 1988; Bretherton, 1987; Main et al., 1985) an important relationship between attachment security and both emotional and cognitive competences in children have been identified (Brenning et al., 2012; Cassidy, 1994; Ding et al., 2014; Mikulincer et al., 2003; Zimmer-Gembeck et al., 2017). Moreover, functionalist and differential perspectives of emotions assume that different associations between attachment quality and ER strategies depend on different emotional states, like sadness, anger or anxiety (Brenning \& Braet, 2013; Clear et al., 2020). Furthermore, a relationship between patterns of insecure attachment and psychopathological outcomes have been proposed (Bowlby, 1980). For instance, associations between insecure attachment and internalizing problems, like depression or anxiety symptoms (Brumariu \& Kerns, 2010; Colonnesi et al., 2011; Groh et al., 2012; Madigan et al., 2013; Spruit et al., 2020), externalizing emotional or behavioral problems (Fearon et al., 2010), early lifetime substance abuse (Schindler, 2019), and other subsequent outcomes, such as suicide-related behavior, have been repeatedly reported. (Serafini et al., 2012; Stepp et al., 2008) Meta-analytic and narrative review revealed that disorganized children show externalizing behavior, but small effects are also found for avoidantly and anxious-resistant attached children (Fearon et al., 2010). However, anxious-resistant attachment is also related with internalizing problems, whilst avoidant attachment is not (see Brumariu \& Kerns, 2010).

So, the different internal models of child-attachment seem to be indirectly linked with the development and maintenance of somatoform complaints (Landa et al., 2012; Vesterling \& Koglin, 2020). Results from studies with adults have already shown that secure and insecure attachment styles lead to different outcomes concerning somatoform complaints 
(Ciechanowski et al., 2002; Maunder \& Hunter, 2001; Meredith et al., 2008; Puig et al., 2012; Waller et al., 2004).

\section{Emotion Regulation}

All states of emotional quality are designed to protect human life by regulating the behavior (Gross \& Thompson, 2007). It is therefore not a matter of eliminating or avoiding so called 'negative' emotions (e. g. anger, sadness, or anxiety), but rather to regulate them in an adequate way. Based on the developmental approach, Thompson (1994) defined emotion regulation as the 'extrinsic and intrinsic processes responsible for monitoring, evaluating, and modifying emotional reactions, especially their intensive and temporal features, to accomplish one's goals'. (Thompson, 1994, pp. 27-28; see also Gross \& Thompson, 2007). Regarding the developmental history of emotion regulation, multiple strategies are already utilized in preschool children (Zeman \& Shipman, 1996). Some of these strategies, described as 'adaptive', are associated with more positive mental outcomes by modifying emotions (Aldao et al., 2010). Others, described as 'maladaptive strategies', are associated with unhealthy emotion modifying and related to psychological symptoms (Aldao et al., 2010). As found in the attachment research, relationships between maladaptive ER strategies and depressive and anxious symptoms and behavior problems have been reported (Braet et al., 2014; Suveg et al., 2009). Emotion suppression, operationalized as an intentional avoidance of emotions by keeping inner feelings inside or thinking of something else, is equally regarded as an unhealthy ER strategy to handle distressing emotions (Chapman et al., 2013). Previous studies indicated associations between ER strategies and both externalizing and internalizing behavior problems (Zeman et al., 2002). Furthermore, previous study results revealed associations between different ER strategies and well-being and/or physiological reactivity, which in turn predicted somatoform complaints (Gross \& John, 2003; Mund \& Mitte, 2011). Focusing on the association between emotion regulation and chronic pain, similar results to those of attachment and somatoform symptoms were found. Koechlin et al. (2018, p.43) reported that emotion regulation might be 'an important secondary risk factor' affecting chronic pain.

\section{Behavior Problems}

Two main broadband dimensions of behavior problems can be distinguished, namely internalizing and externalizing behavior problems which encompass various narrow-band syndromes (Achenbach, 1966, 1995). Internalizing symptoms are associated with severe inner tension, unpleasant feelings of psychological unease, being withdrawn and introversion, e.g., anxiety, depression, social withdraw, or somatoform complaints
(Forns et al., 2011). Affected persons tend to put the blame on themselves, do not trust their own self-efficacy, and often feel helpless and overburdened (Tandon et al., 2009). In contrast, externalizing behavior problems are often focused outwards, and are thus easily observable by others (Forns et al., 2011). Internalizing and externalizing behavior problems are related to both child-attachment and ER strategies. Insecure attachment in children, as well as the use of unhealthy ER strategies predict psychopathologic developmental outcomes (Bowlby, 1980). Moreover, in the DSM-5 (American Psychiatric Association, 2013) diagnostic criteria for depression and anxiety, which count as a form of internalizing behavior problems, include vegetative symptoms. Likewise, the description of "Somatoform disorders" in DSM-5 (American Psychiatric Association, 2013) notes co-occurring internalizing mental symptoms. Furthermore, associations between internalizing problems and somatoform complaints, as well as between externalizing problems and somatoform complaints have been found in previous research studies (Egger et al., 1999; Lieb et al., 2007).

\section{The Current Study}

Analyzing the research results, we maintain that there is not only one sole factor which influences somatoform complaints, but rather that there is an interplay between biological, psychological, and social factors (Koechlin et al., 2018; Maunder \& Hunter, 2001; Landa et al., 2012; Meredith et al., 2008; Vesterling \& Koglin, 2020). However, behavior problems have clearly been found to directly predict somatoform complaints. Apart from that, it seems as if many individual factors, particularly attachment and ER strategies, play an important role in influencing each other in a complex interplay of mediation and moderation mechanisms.

In light of the previously unsatisfactory understanding of the complex cause-effect relationships, the aim of this article is to explore the interplay between child attachment dimensions, ER strategies, behavior problems, and somatoform complaints in middle childhood, in order to get an extensive overview of the underlying predicting pathways.

Based on the aforementioned studies, we assume that (1) the individual internalized working model of attachment in children predicts the use of a preferred strategy of emotion regulation, (2) which in turn influences the development of behavior problems, and (3) the level of somatoform complaints in children. We also assume (4) a direct effect from the dimension of attachment anxiety on internalizing behavior problems, and (5) a direct effect from the dimension of attachment avoidance on externalizing behavior problems. Based on previous 
Fig. 1 illustrates the hypothesized associations between the variables included in the model. Expected significant associations are presented with solid lines, and those which we expected not to be significant are represented by dashed lines

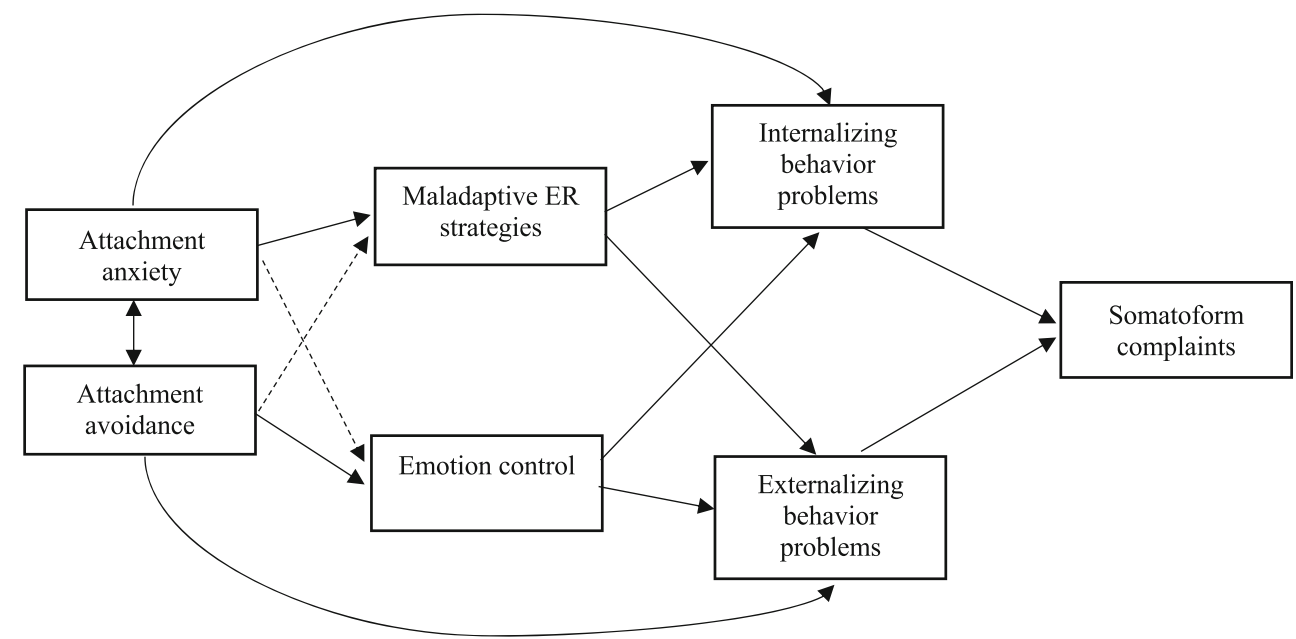

research we hypothesized the following associations presented in Fig. 1.

\section{Methods}

\section{Participants and Procedure}

The participants were 221 primary school students (female $n=115$; male $n=105$ [one not reported gender $n=220$ ]; $M$ age [eleven not reported age $n=210$ ] $=9.70$ years $(\mathrm{SD})=.56$ ) attending grade 4 . The reported sample is a subsample (Timepoint 1) of the longitudinal study "Impact factors and conditions of somatoform symptoms in childhood within familial and school contexts" listed in the German Clinical Trails Register (DRKS-ID: DRKS00012444) and the WHO International Clinical Trials Registry Platform. Participants were recruited between February 2018 and June 2019. The prerequisites for study participation were (1) the child is currently attending the fourth year of primary school, (2) participants have enough language abilities to understand and complete the questionnaire, and (3) an informed written consent of the parents (teachers) agreeing to participate in the study is available. Furthermore, no additional specific exclusion criteria were defined for the study. 124 primary schools were contacted and informed about the study via e-mail. After that, we called the schools to see if they want to participate. In the end, 29 primary schools agreed to partake. Thereafter, 1797 informed consents were distributed to the children and their parents via teaching personnel. 254 families agreed to participate and signed the consent forms; yet only 221 returned a completed questionnaire. From 33 families no questionnaire reply was received. The current study corresponds to the ethical principles for medical research examining human subjects formulated by the Declaration of Helsinki and to the Medical Ethical Committee of the Carl von Ossietzky University of Oldenburg.

\section{Measures}

Attachment In early childhood, observational methods for assessing attachment styles are plausible (Ainsworth et al., 1978), yet during middle childhood observational methods cannot fully capture the representational attachment, which manifests not only in behavioral tendencies but rather encompasses cognitive and mental aspects. This theoretical idea influenced our choice to measure attachment dimensionally in a self-report questionnaire (Kerns \& Brumariu, 2018; Ross, 2004). For this, we utilized the self-report questionnaire 'Adaption of the Experiences in Close Relationship ScaleRevised for Use with Children and Adolescents' (ECR-RC) ${ }^{1}$ (Brenning et al., 2011). The questionnaire assesses two insecure child-mother attachment representations, namely attachment-anxiety and attachment-avoidance (Brennan et al., 1998; Fraley \& Spieker, 2003; Mikulincer \& Shaver, 2007). The ECR-RC consist of 36 Items, with previous psychometric evaluations revealing the reliability and validity to be satisfactory (see Brenning et al., 2012). Children responded on a 7 -point scale $(1=$ not at all to $7=$ very much $)$ to statements concerning the relationship with their mothers. These are related to the respective different dimensions of attachment anxiety (e. g. 'I'm afraid my mother will stop loving me') and attachment avoidance (e. g. 'It's not easy for me to tell my mother a lot about myself).

Emotion Regulation The utilized ER strategies were assessed with the 'Fragebogen zur Erhebung der Emotionsregulation bei Kindern und Jugendlichen' (FEEL-KJ), a valid and reliable questionnaire of ER strategies in childhood and adolescent (Cracco et al., 2015; Grob \& Smolenski, 2009). The authors differentiate ER strategies into adaptive and maladaptive strategies, based on the subjective wellbeing of children

\footnotetext{
${ }^{1}$ (ECR-RC), Brenning et al., 2011), Questionnaire translated into German with the friendly permission of the author)
} 
and adolescents. The self-report version for children aged 8 to 19 years was used to examine ER strategies, concerning the feelings of anger, anxiety, and sadness in a 90-items questionnaire (see Grob \& Smolenski, 2009). 15 ER strategy scales were described. 7 scales -'Problem-Oriented Behavior', 'Distraction', 'Lift Mood', 'Accept Feelings', 'Forgetting', 'Cognitive Problem Solving', 'Reappraisal' to assess adaptive ER strategies and 5 scales - 'Giving up', 'Withdrawal Behavior', 'Rumination', 'Self-devaluation' and 'Aggressive Behavior' to assess maladaptive ER strategies. Furthermore, three additional ER strategies - 'Emotion Control', 'Expression' and 'Social Support' - can be assessed. Children rated their response to the statements on a 5-point scale $(1=$ never to $5=$ almost always $)$.

Child Emotional and Behavior Problems Child emotional and behavior problems were assessed with the 'Child Behavior Checklist' CBCL/6-18R; a frequently used, valid, and reliable instrument. (Achenbach \& Rescorla, 2001). The CBCL/6$18 \mathrm{R}$ includes 104 Items on eight problem scales ('Anxious/ depressed', 'Withdrawn/depressed', 'Somatic Complaints', 'Social Problems', 'Thought Problems', 'Attention Problems', 'Rule Breaking Behavior', and 'Aggressive Behavior'). From which two superordinate scales can be formed, namely Internalizing problems ('Anxious/depressed', 'Withdrawn-depressed', and 'Somatic Complaints') and Externalizing Problems ('Rule-Breaking Behavior' and 'Aggressive Behavior') (Achenbach et al., 2008). Parents rated the items (about their child's behavior observed in the last six months), on a 3 -point-scale $(0=$ not true, $1=$ sometime/ somewhat true, 2 = often true/very true). In order to avoid data overlaps in the statistical analysis we remove the 'Somatic complaints' scale from the 'Internalizing problem' scale.

\section{Data Analysis}

To estimate the regression weights with Full Information Maximum Likelihood (FIML), we conducting a Little-MCAR test (Little, 1988). The resulting not significant $p$ value indicates that the data are missing completely at random. Based on this we handle the missing data with FIML method. Furthermore, we accepted an $80 \%$ completion of each involved scale as sufficient for statistical calculations. Residuals were approximately normally distributed and multicollinearity did not seem to be a problem (VIF values $<5$ ) as shown in Table 1 . To prove the hypothesized path analysis model (see Fig. 1) the structural equation modelling (SEM) program AMOS 26.0 was used (IBM®) SPSS $\left.{ }^{\circ} A \operatorname{mos}^{\text {TM}} 26,2019\right)$. By choosing the maximumlikelihood method, the multiple path coefficients could be estimated simultaneously and an estimate global model fit (between model and data) was generated. These are shown in Fig. 2.

Assessing the goodness of fit between the theoretical model structure and the empiric data pool, several model fit indicators are presented. Significant chi-square results would support rejecting the zero-hypothesis, which claims that the covariance matrices are identical. Therefore, a nonsignificant result of $p>.05$ indicates a good model fit. We also report the Root Mean Square Error of Approximation (RMSEA) to check if the model fits the reality sufficiently. RMSEA values $<.08$ indicate an acceptable model fit. Furthermore, the incremental fit index NFI (Normed Fit Index) and its revised form CFI (Comparative Fit Index) are reported. An NFI-value of $>.90 / \geq .95$ and a CFI value $>.90 / \geq .95$ indicates a good model fit. Finally, the relative/ normed chi-square is also performed. If the relation between $\chi 2$-value and degrees of freedom is $\leq 2.00$ an adequate model fit can be assumed.

Sample Size Justification To determine whether or not the number of included subjects constitute a large enough sample to detect possible effects for the current research question, a power analysis was conducted (Faul et al., 2007; Faul et al., 2009). A priori tests to detect the required sample size yielded a sample size of $N=146$, when an effect size $\mathrm{f}^{2}=.15, \alpha$ err prob. $=.05$, power $(1-\beta$ err prob $)=.95$ and a number of six predictors are included.

\section{Results}

\section{Preliminary Analyses}

Table 1 illustrates the bivariate correlations between the included variables. Means, standard divisions, $\alpha$-coefficients and VIF values are also presented. In line with previous study results our results revealed significant correlations between attachmentanxiety and attachment-avoidance (Conradi et al., 2006). Furthermore, significant correlations between attachment anxiety and maladaptive ER strategies, emotion control, internalizing problems, externalizing problems and somatoform complaints are found. Significant relationships between attachment avoidance and emotion control, as well as internalizing and externalizing problems, are also shown. Furthermore, maladaptive ER strategies are significant related to emotion control, internalizing and externalizing problems, as well as somatoform complaints. Moreover, emotion control is significantly related to both internalizing and externalizing problems. Significant correlations between internalizing and externalizing problems are also revealed. Finally, somatoform complaints are significantly positive related to internalizing and externalizing behavior problems.

T-test results showed no significant differences between boys $(M=1.76, \mathrm{SD}=1.99)$ and girls $(M=2.09 \mathrm{SD}=2.07)$ on somatoform complaints: $\mathrm{t}(218)=-1.19, p=.236$; indicating that gender does not have an effect on the level of somatoform symptoms in in our sample. 
Table 1 Correlations between mother-child attachment, emotion regulation strategies, behavior problems and somatoform complaints in childhood; means, standard divisions, $\alpha$-coefficients of included questionnaires and VIF values of the collinearity statistics

\begin{tabular}{|c|c|c|c|c|c|c|c|c|c|c|}
\hline Variables & M & SD & $\alpha$ & VIF & 1 & 2 & 3 & 4 & 5 & 6 \\
\hline 1.Attachment anxiety & 35.82 & 13.18 & .73 & 1.46 & & & & & & \\
\hline 2.Attachment avoidance & 41.04 & 16.27 & .82 & 1.50 & $.547 * *$ & & & & & \\
\hline 3.Maladaptive ER strategies & 76.45 & 14,93 & .80 & 1.09 & $.234 * *$ & .078 & & & & \\
\hline 4.Emotion control & 15.80 & 4.78 & .64 & 1.14 & $.144 *$ & $.295 * *$ & $.160^{*}$ & & & \\
\hline 5.Internalizing problems & 4.43 & 5.05 & .88 & 1.39 & $.224 * *$ & $.149^{*}$ & $.286^{* *}$ & $.133 *$ & & \\
\hline 6.Externalizing problems & 5.79 & 5.85 & .89 & 1.41 & $.155^{*}$ & $.158^{*}$ & $.249 * *$ & $.246 * *$ & $.464 * *$ & \\
\hline 7.Somatoform complaints & 1.98 & 2.26 & .69 & - & $.161 *$ & -.112 & $.204 * *$ & .006 & $.359 * *$ & $.366^{* *}$ \\
\hline
\end{tabular}

$M$ mean, $S D$ standard division, $\alpha$ Cronbachs Alpha, (Internalizing problem scale without the somatoform complain scale), $V I F$ variance inflation factors; Attachment anxiety and avoidance $=$ Adaption of the Experiences in Close Relationship Scale-Revised for Use with Children and Adolescents $($ ECRRC) (Brenning et al., 2011), Maladaptive ER strategies and Emotion control = FEEL-KJ (Grob \& Smolenski, 2009), Internalizing and externalizing behavior problems and somatic complaints $=$ Child Behavior Checklist/6-18 CBCL/6-18 R (Achenbach \& Rescorla, 2001), ER = emotion regulation, $* p<.05, * * p<.01, * * * p<.001$

\section{Path-Analysis}

Based on the hypothesized model shown in Fig. 1 we examined the overall model fit. It should be noted that an intercorrelation between attachment anxiety and attachment avoidance $(.547, \mathrm{p}=<.001)$, attachment avoidance and error of somatoform complaints $(-.209, \mathrm{p}=<.01)$ are permitted, as well as error correlations between the emotional / behavioral problems $(.408, \mathrm{p}=<.001)$ and between the ER strategies $(.153, \mathrm{p}=<.05)$. Calculations revealed a good fit of the initial model to data $\left(\mathrm{X}^{2}=\mathrm{p} .798, \mathrm{X}^{2} / \mathrm{df}=.415, \mathrm{NFI}=.994 ; \mathrm{CFI}=\right.$ 1.000, RMSEA $=.000$ ). The direct effects of the path analysis are presented in Fig. 2. We decided not to depict the intercorrelation paths to provide a better overview. As expected, path analysis revealed significant direct positive associations between attachment anxiety and internalizing behavior ( $\beta=.142, p<.05)$, as well as high significant direct positive associations between both internalizing $(\beta=.224, p<.001)$ and externalizing behavior $(\beta=.275, p<.001)$ and somatoform complaints. Furthermore, the two different insecure attachment dimensions predict different ER strategies. As hypothesized attachment-anxiety predicts maladaptive ER strategies $(\beta=.274, p<.001)$, and attachment-avoidance affects emotion control $(\beta=.309, p<.001)$. Significant paths are also found between maladaptive ER strategies and internalizing behavior problems $(\beta=.241, \mathrm{p}<.001)$, as well as on externalizing behavior $(\beta=.213, \mathrm{p}<.001)$. Moreover, a significant path between emotion control and externalizing
Fig. 2 Direct effects of the final model are presented. The significant standardized regression weights are shown and illustrated with solid lines. For not significant associations dashed lines were used

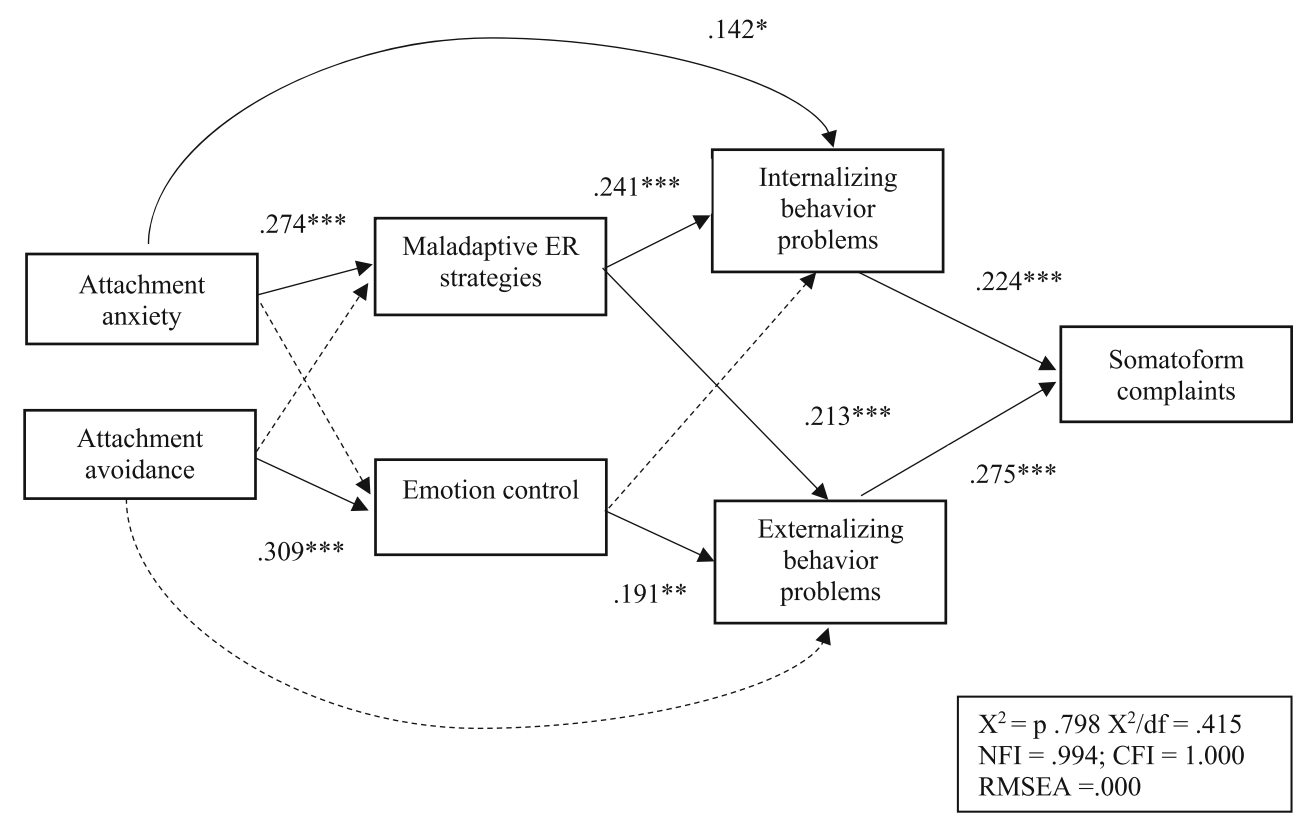


behavior problems $(\beta=.191, p<.01)$ was found. The explained variance of somatoform complaints in this model amounts to a total of $18 \%$.

To test if the revealed specific indirect effects differ from zero, we conducted bootstrapping in AMOS. Results revealed that somatoform complaints are not only affected directly by behavior problems. Maladaptive ER strategies show a significant indirect effect on somatoform complaints $(\beta=.113$, $p<.01$ ), mediated by both internalizing behavior and externalizing behavior problems. Moreover, emotion control is also indirectly related to somatoform complaints $(\beta=.069$, $p<.01$ ), mediated by externalizing problems. Furthermore, a significant indirect effect is found for attachment anxiety on somatoform complaints $(\beta=.061, \mathrm{p}<.01)$, mediated by maladaptive ER strategies on the pathway of attachment anxiety influencing maladaptive ER strategies influencing internalizing and externalizing problems and in turn somatoform complaints.

\section{Conclusions}

The main outcomes of the current study confirmed by pathanalysis are (1) the individual internalized working model of attachment in children predicts the use of a preferred strategy of emotion regulation, (2) which in turn influence the development of behavior problems, and (3) the level of somatoform complaints in children.

Corresponded with attachment theory, our results revealed that children with high levels of attachment avoidance preferably use the strategy of 'emotion control' to handle 'negative' emotions (see Clear et al., 2020; Mikulincer \& Shaver, 2007). In contrast, the association between high levels of attachment anxiety and 'emotion control' shown in the primary correlation analysis could no longer be shown in the path analysis, but instead a high significant path on 'maladaptive ER strategies (Ainsworth et al., 1978; Bowlby, 1980; Brumariu, 2015; Cassidy, 1994; Clear et al., 2020; Kotler et al., 1994; Main et al., 1985; Shaver \& Mikulincer, 2002). This enables us to distinguish between two main developmental paths with regards to the occurrence of somatoform complaints. We further hypothesized that the ER strategies would predict behavior problems. In all paths, except one, this assumption was confirmed. 'Maladaptive ER strategies' predicted both internalizing and externalizing behavior significantly, and 'emotion control' predicted externalizing behavior. A possible explanation for this might be an unsuccessful and overburdened attempt to regulate emotions with unhealthy ER strategies, which in turn leads only to an apparent emotional regulation. These children may suffer from an ongoing increased level of neurophysiological arousal, which could be one factor contributing to an increased level of behavior problems (Scarpa et al., 2010; Schoorl et al., 2016; Spangler \& Grossmann,
1993.) Concerning 'emotion control', a possible explanation comes from research that shows a relationship between a decreased basic arousal and emotion suppression. The 'low arousal theory'(van Goozen et al., 2007) states that there is an association between low arousal and seeking for stimulating behavior, which may result in externalizing behavior problems (Schoorl et al., 2016). Finally, significant results support the theory-based assumption that behavior problems predict somatoform complaints. As a further contradiction to our hypothesis, we found no significant direct path between attachment avoidance and externalizing behavior problems. These results fit in well with the existing heterogeneous results of the actual state of research, as elaborated in earlier sections.

Our study demonstrated that there are two developmental path ways leading to the occurrence of somatoform complaints in children, depending on the two insecure attachment dimensions and mediated through different strategies of emotion regulation. This study imparts a first insight into the underlying mechanisms describing the occurrence of somatoform complaints. To assess the interplay of vital components and their interdependencies to explain the occurrence of somatoform complaints, further interdisciplinary research, including both medicine and psychology, is needed. It is important to consider the different insecure attachment dimensions in a more detailed way when developing prevention programs and therapeutic interventions.

\section{Practical Implications}

Somatoform complaints and seeking for medical help is very common in childhood (Kelly et al., 2010). Consequently, a range of different intervention approaches are described. In accordance with the hypotheses in this article, results show that children with high levels of attachment anxiety prefer maladaptive ER strategies, and children with high levels of attachment avoidance prefer emotion control to regulate their emotions. Furthermore, the association between ER strategies and somatoform complaints are mediated by behavior problems. This interplay needs to be given greater attention, particularly with regard to both the development of psychotherapeutic interventions and prevention programs for children with somatoform complaints. Treatment approaches should consider a detailed assessment of the child's attachment quality, their use of ER strategies, and possible comorbid psychiatric problems (see Campo \& Fritz, 2001). Based on our results, this approach is indispensable for the development of new, more differentiated psychotherapeutic treatments. The different paths in our study indicate the need for specific interventions for children with different manifestations of attachment quality, ER strategies, and behavior problems. For children with high levels of attachment avoidance it is essential to re-learn to perceive their 'negative' feelings without fear. Only in a subsequent step, will they be able to 
use this recovered competence to learn new adaptive ER strategies to handle their emotions. In accordance with the theoretical background, the use of adaptive ER strategies is negatively related to behavior problems (Aldao et al., 2010), which in turn may also leads to a reduction of somatoform complaints. For children with high levels of attachment anxiety, emotion control does not seem to be the primary problem. They are able to perceive and express their feelings. In these cases, it is more important to learn how to deal with 'negative' emotions in an age-appropriate and self-reliant way. Especially, learning to evaluate feelings in an adequate, not catastrophizing way, is an important skill for these children. Psychotherapeutic interventions and preventions approaches could be implemented at various points of development. For example, early support can promote an adequate interaction between children and caregiver leading to the development of a secure attachment style as a preventative measure to somatoform complaints in childhood (see Wright \& Edginton, 2016). In later developmental stages preventative measures or intervention programs should be exploited, namely those that promote emotional competences like emotion knowledge and emotion regulation (see Izard et al., 2011). Additionally, a therapeutic treatment targeted at the comorbid psychiatric externalizing and internalizing behavior problems could reduce the incidence of somatoform symptoms in childhood (see Howard \& Kendall, 1996).

\section{Limitations}

The internal consistency of the scales 'emotion control' and 'somatoform complaints' is questionable $(\alpha=.64$; $\alpha=.69$ ). A better reliability might possibly have helped to explain more than $18 \%$ of variation. Furthermore, the ER strategies were solely assessed via self-report by children. This method presupposes that children are aware of the ER strategies they use to regulate 'negative" emotions. Moreover, using self-report questionnaires entails the risk that children basically refer to recent or intensive emotional experiences. A similar issue arises when assessing 'somatoform complaints' through parental report. If children do not tell their parents about their symptoms, this could lead to a response bias in measuring results. Due to these methodological limitations, we recommend further research to combine various survey methods assessing each variable, like self-, parental-, or teachers- report, and observational methods. Although our results support most of our hypothesized paths, our model might suffer from not including other vital factors. Therefore, it would be appropriate in further research to examine temperament, parenting styles, processes of emotion perception and awareness, physical arousal, and physical health. The same applies to the inclusion of other confounders, like sociodemographic data.
Authors' Contributions All authors contributed to the study conception and design. Material preparation, data collection and analysis were performed by Christina Vesterling and Prof. Dr. Ute Koglin. The first draft of the manuscript was written by Christina Vesterling and all authors commented on previous versions of the manuscript. All authors read and approved the final manuscript.

The article is based primarily on Christina Vesterling's dissertation project (topic: "Impact factors and conditions of somatoform symptoms in childhood within familial and school contexts"). The submitted manuscript will form part of Christina Vesterling's cumulative dissertation, so Christina Vesterling is listed as principal author.

Funding Open Access funding enabled and organized by Projekt DEAL. The research project "Impact factors and conditions of somatoform symptoms in childhood within familial and school contexts" is funded by the Carl von Ossietzky University of Oldenburg, Department of Special Needs Education \& Rehabilitation. No further funding was received to assist with the preparation of this manuscript.

Data Availability Research data are not shared/data will not be deposited.

\section{Declarations}

The research project "Impact factors and conditions of somatoform symptoms in childhood within familial and school contexts" corresponds to the ethical principles for medical research examining human subjectsformulated by the Declaration of Helsinki and to the Medical Ethical Committee of the Carl von Ossietzky University of Oldenburg (Germany).

Employment The authors (Christina Vesterling and Prof. Dr. Ute Koglin) are employees of the Carl von Ossietzky University of Oldenburg.

Conflict of Interest On behalf of all authors, the corresponding author states that there is no conflict of interest.

Open Access This article is licensed under a Creative Commons Attribution 4.0 International License, which permits use, sharing, adaptation, distribution and reproduction in any medium or format, as long as you give appropriate credit to the original author(s) and the source, provide a link to the Creative Commons licence, and indicate if changes were made. The images or other third party material in this article are included in the article's Creative Commons licence, unless indicated otherwise in a credit line to the material. If material is not included in the article's Creative Commons licence and your intended use is not permitted by statutory regulation or exceeds the permitted use, you will need to obtain permission directly from the copyright holder. To view a copy of this licence, visit http://creativecommons.org/licenses/by/4.0/.

\section{References}

Achenbach, T. M. (1966). The classification of children's psychiatric symptoms: A factor analytic study. Psychological Monographs, 80, 1-37.

Achenbach, T. M. (1995). Empirically based assessment and taxonomy: Applications to clinical research. Psychological Assessment, 7(3), 261-274.

Achenbach, T. M., \& Rescorla, L. A. (2001). Manual for the ASEBA school-age forms \& profiles. University of Vermont, Research Center for Children, Youth, and Families. 
Achenbach, T. M., Becker, A., Döpfner, M., Heiervang, E., Roessner, V., Steinhausen, H. C., \& Rothenberger, A. (2008). Multicultural assessment of child and adolescent psychopathology with ASEBA and SDQ instruments: Research findings, applications, and future directions. Journal of Child Psychology and Psychiatry, 49, 251-275.

Ainsworth, M. D. S., Blehar, M. C., Waters, E., \& Wall, S. (1978). Patterns of attachment. Erlbaum.

Aldao, A., Nolen-Hoeksema, S., \& Schweizer, S. (2010). Emotionregulation strategies across psychopathology: A meta-analytic review. Clinical Psychology Review, 30, 217-237.

American Psychiatric Association. (1980). Diagnostic and statistical manual of mental disorders (3th ed). Washington, DC: Author.

American Psychiatric Association. (1987). Diagnostic and statistical manual of mental disorders (3rd ed., revised). Washington, DC: Author

American Psychiatric Association. (1994). Diagnostic and statistical manual of mental disorders (4th ed). Washington, DC: Author.

American Psychiatric Association. (2000). Diagnostic and statistical manual of mental disorders (4th ed., text rev.). Washington, DC: Author.

American Psychiatric Association. (2013). Diagnostic and statistical manual of mental disorders (5th ed). Washington, DC: Author.

Bernstein, G. A., Massie, E. D., Thuras, P. D., Perwien, A. R., Borchardt, C. M., \& Crosby, R. D. (1997). Somatic symptoms in anxiousdepressed school refusers. Journal of the American Academy of Child and Adolescent Psychiatry, 36, 661-668.

Bowlby, J. (1969/1982). Attachment and Loss, Volume 1: Attachment. New York: Basic Books.

Bowlby, J. (1973). Attachment and Loss, Volume 2: Separation, Anger and Anxiety. New York: Basic Books.

Bowlby, J. (1980). Attachment and Loss, Volume 3: Loss, Sadness and Depression. New York: Basic Books.

Bowlby, J. (1988). A secure base. Basic Books.

Braet, C., Theuwis, L., Van Durme, K., Vandewalle, J., Vandevivere, E., Wante, L., ..., Goossens, L. (2014). Emotion regulation in children with emotional problems. Cognitive Therapy and Research, 38, 493-504.

Brennan, K. A., Clark, C. L., \& Shaver, P. R. (1998). Self-report measurement of adult attachment: An integrative overview. In J. A. Simpson \& W. S. Rholes (Eds.), Attachment theory and close relationships (pp. 46-76). The Guilford Press.

Brenning, K., \& Braet, C. (2013). The emotion regulation model of attachment: An emotion-specific approach. Personal Relationships, 20, 107-123.

Brenning, K., Soenens, B., Braet, C., \& Bosmans, G. (2011). An adaptation of the experiences in close relationships scale-revised for use with children and adolescents. Journal of Social and Personal Relationships, 28, 1048-1072.

Brenning, K., Soenens, B., Braet, C., \& Bosmans, G. (2012). Attachment and depressive symptoms in middle childhood and early adolescence: Testing the validity of the emotion regulation model of attachment. Personal Relationships, 19, 445-464.

Bretherton, I. (1987). New perspectives on attachment relations: Security, communication, and internal working models. In J. Osofsky (Ed.), Handbook of infant development (pp. 1061-1100). Wiley.

Brumariu, L. (2015). Parent-child attachment and emotion regulation. New Directions for Child and Adolescent Development, 148, 31-45.

Brumariu, L. E., \& Kerns, K. A. (2010). Parent-child attachment and internalizing symptoms in childhood and adolescence: A review of empirical findings and future directions. Development and Psychopathology, 22, 177-203.

Campo, J. V., \& Fritz, G. (2001). A management model for pediatric somatization. Psychosomatics, 42, 467-476.

Cassidy, J. (1994). Emotion regulation: Influences of attachment relationships. Monographs of the Society for Research in Child Development, 59(2/3), 228-249.

Chapman, B. P., Fiscella, K., Kawachi, I., Duberstein, P., \& Muennig, P. (2013). Emotion suppression and mortality risk over a 12-year follow-up. Journal of Psychosomatic Research, 75(4), 381-385.
Ciechanowski, P. S., Walker, E. A., Katon, W. J., \& Russo, J. E. (2002). Attachment theory: A model for health care utilization and somatization. Psychosomatic Medicine, 64(4), 660-667.

Clear, S. J., Gardner, A. A., Webb, H. J., \& Zimmer-Gembeck, M. J. (2020). Common and distinct correlates of depression, anxiety, and aggression: Attachment and emotion regulation of sadness and anger. Journal of Adult Development, 27, 181-191.

Colonnesi, C., Draijer, E., Stams, G., Bruggen, C., Bögels, S., \& Noom, M. (2011). The relation between insecure attachment and child anxiety: A meta-analytic review. Journal of clinical child and adolescent psychology: the official journal for the Society of Clinical Child and Adolescent Psychology, American Psychological Association, Division, 53(40), 630-645.

Conradi, H.-J., Gerlsma, C., van Duijn, M., \& de Jonge, P. (2006). Internal and external validity of the experiences in close relationships questionnaire in an American and two Dutch samples. European Journal of Psychiatry, 20(4), 258-269.

Cracco, E., Van Durme, K., \& Braet, C. (2015). Validation of the FEEL$\mathrm{KJ}$ : An instrument to measure emotion regulation strategies in children and adolescents. PLoS One, 10(9), e0137080. https://doi.org/ 10.1371/journal.pone.0137080.

Dilling, H. (2011). Internationale Klassifikation psychischer Störungen: ICD-10 Kapitel V (F); klinisch-diagnostische Leitlinien (8. überarb. Aufl. unter Berücksichtigung der Änderungen entsprechend ICD10-GM 2011). Huber.

Ding, Y. H., Xu, X., Wang, Z. Y., Li, H. R., \& Wang, W. P. (2014). The relation of infant attachment to attachment and cognitive and behavioural outcomes in early childhood. Early Human Development, 90(9), 459-464.

Egger, H. L., Costello, E. J., Erkanli, A., \& Angold, A. (1999). Somatic complaints and psychopathology in children and adolescents: Stomach aches, musculoskeletal pains, and headaches. Journal of the American Academy of Child \& Adolescent Psychiatry, 38(7), 852-860.

Faul, F., Erdfelder, E., Lang, A.-G., \& Buchner, A. (2007). G*power 3: A flexible statistical power analysis program for the social, behavioral, and biomedical sciences. Behavior Research Methods, 39, 175-191.

Faul, F., Erdfelder, E., Buchner, A., \& Lang, A.-G. (2009). Statistical power analyses using $\mathrm{G}^{*}$ power 3.1: Tests for correlation and regression analyses. Behavior Research Methods, 41, 1149-1160.

Fearon, R., Bakermans-Kranenburg, M., van IJzendoorn, M., Lapsley, A. M., \& Roisman, G. (2010). The significance of insecure attachment and disorganization in the development of Children's externalizing behavior: A meta-analytic study. Child Development, 81, 435-456.

Forns, M., Abad, J., \& Kirchner, T. (2011). Internalizing and externalizing problems. In R. J. R. Levesque (Ed.), Encyclopedia of adolescence. Springer.

Fraley, R., \& Spieker, S. (2003). Are infant attachment patterns continuously or categorically distributed? A taxometric analysis of strange situation behavior. Developmental Psychology, 39, 387-365.

Grob, A., \& Smolenski, C. (2009). Fragebogen zur Erhebung der Emotionsregulation bei Kindern und Jugendlichen. Testzentrale. Hogrefe.

Groh, A., Roisman, G., Van IJzendoorn, M., Bakermans-Kranenburg, M., \& Fearon, R. (2012). The significance of insecure and disorganized attachment for Children's internalizing symptoms: A metaanalytic study. Child Development, 83(2), 591-610.

Gross, J. J., \& John, O. (2003). Individual differences in two emotion regulation processes: Implications for affect, relationships, and wellbeing. Journal of Personality and Social Psychology, 85, 348-362.

Gross, J. J., \& Thompson, R. A. (2007). Emotion regulation: Conceptual foundations. In J. J. Gross (Ed.), Handbook of emotion regulation (pp. 3-24). Guilford Press.

Howard, B. L., \& Kendall, P. C. (1996). Cognitive-behavioral family therapy for anxiety-disordered children: A multiple-baseline evaluation. Cognitive Therapy and Research, 20, 423-443. 
Izard, C. E., Cavadel, E., Finlon, K., Krauthamer-Ewing, E. S., Johnson, S., \& Seidenfeld, A. (2011). Emotion knowledge, emotion utilization, and emotion regulation. Emotion Review, 3, 44-52.

Kelly, C., Molcho, M., Doyle, P., \& Gabhainn, S. N. (2010). Psychosomatic symptoms among schoolchildren. International Journal of Adolescent Medicine and Health, 22(2), 229-235.

Kerns, K., \& Brumariu, L. (2018). Attachment in middle childhood. In J. Cassidy \& P. Shaver (Eds.), Handbook of Attachment, Theory, Research, and Clinical Applications (pp. 349-365). The Guilford Press.

Koechlin, H., Coakley, R., Schechter, N., Werner, C., \& Kossowsky, J. (2018). The role emotion regulation in chronic pain: A systematic literature review. Journal of Psychosomatic Research, 107, 38-45.

Kotler, T., Buzwell, S., Romeo, Y., \& Bowland, J. (1994). Avoidant attachment as a risk factor for health. The British Journal of Medical Psychology, 67(3), 237-245.

Landa, A., Peterson, B. S., \& Fallon, B. A. (2012). Somatoform pain: A developmental theory and translational research review. Psychosomatic Medicine, 74, 717-727.

Lieb, R., Meinlschmidt, G., \& Araya, R. (2007). Epidemiology of the association between somatoform disorders and anxiety and depressive disorders: An update. Psychosomatic Medicine, 69, 860-863.

Little, R. J. A. (1988). A test of missing completely at random for multivariate data with missing values. Journal of the American Statistical Association, 83(404), 1198-1202.

Madigan, S., Atkinson, L., Laurin, K., \& Benoit, D. (2013). Attachment and internalizing behavior in early childhood: A meta-analysis. Developmental Psychology, 49(4), 672-689.

Main, M., Kaplan, N., \& Cassidy, J. (1985). Security in infancy, childhood, and adulthood: A move to the level of representation. Monographs of the Society for Research in Child Development, 50(1/2), 66-104.

Maunder, R. G., \& Hunter, J. J. (2001). Attachment and psychosomatic medicine: Developmental contributions to stress and disease. Psychosomatic Medicine, 63, 556-567.

Meredith, P., Ownsworth, T., \& Strong, J. (2008). A review of the evidence linking adult attachment theory and chronic pain: Presenting a conceptual model. Clinical Psychology Review, 28, 407-429.

Mikulincer, M., \& Shaver, P. R. (2007). Attachment patterns in adulthood: Structure, dynamics and change. Guilford Press.

Mikulincer, M., Shaver, P. R., \& Pereg, D. (2003). Attachment theory and affect regulation: The dynamics, development, and cognitive consequences of attachment-related strategies. Motivation and Emotion, 27(2), 77-102.

Mund, M., \& Mitte, K. (2011). The costs of repression: A meta-analysis on the relation between repressive coping and somatic diseases. Health Psychology, 31(5), 640-649.

Puig, J., Englund, M., Simpson, J., \& Collins, W. (2013). Predicting adult physical illness from infant attachment: a prospective longitudinal study. Health psychology : official journal of the Division of Health Psychology. American Psychological Association, 32(4), 409-417 .

Ross, T. (2004). Attachment representation, attachment style or attachment pattern? Usage of terminology in attachment theory. In F. Pfäfflin \& G. Adchead (Eds.), At matter of security. The application of attachment theory to forensic psychiatry and psychotherapy (pp. 57-84). Jessica Kingsley.

Scarpa, A., Haden, S. C., \& Tanaka, A. (2010). Being hot-tempered: Autonomic, emotional, and behavioral distinctions between childhood reactive and proactive aggression. Biological Psychology, 84(3), 488-496.

Schindler, A. (2019). Attachment and substance use disorders-theoretical models, empirical evidence, and implications for treatment. Frontiers in Psychiatry, 10, 727.

Schoorl, J., Van Rijn, S., De Wied, M., Van Goozen, S. H., \& Swaab, H. (2016). Variability in emotional/behavioral problems in boys with oppositional defiant disorder or conduct disorder: The role of arousal. European Child \& Adolescent Psychiatry, 25(8), 821-830.

Serafini, G., Pompili, M., Innamorati, M., Rihmer, Z., Sher, L., \& Girardi, P. (2012). Can cannabis increase the suicide risk in psychosis? A critical review. Current Pharmaceutical Design, 18(32), 5165-5187.

Shaver, P. R., \& Mikulincer, M. (2002). Attachment-related psychodynamics. Attachment \& Human Development, 4, 133-161.

Spangler, G., \& Grossmann, K. E. (1993). Biobehavioral organization in securely and insecurely attached infants. Child Development, 64, 1439-1450.

Spruit, A., Goos, L., Weenink, N., Rodenburg, R., Niemeyer, H., Stams, G. J., \& Colonnesi, C. (2020). The relation between attachment and depression in children and adolescents: A multilevel meta-analysis. Clinical Child and Family Psychology Review, 23(1), 54-69.

Stepp, S. D., Morse, J. Q., Yaggi, K. E., Reynolds, S. K., Reed, L. I., \& Pilkonis, P. A. (2008). The role of attachment styles and interpersonal problems in suicide-related behaviors. Suicide \& LifeThreatening Behavior, 38(5), 592-607.

Suveg, C., Hoffman, B., Zeman, J. L., \& Thomassin, K. (2009). Common and specific emotion-related predictors of anxious and depressive symptoms in youth. Child Psychiatry \& Human Development, 40, 223-239.

Tandon, M., Cardeli, E., \& Luby, J. (2009). Internalizing disorders in early childhood: A review of depressive and anxiety disorders. Child and Adolescent Psychiatric Clinics of North America, 18, 593-610.

Thompson, R. A. (1994). Emotion regulation: A theme in search of definition. Monographs of the Society for Research in Child Development, 59, 25-52.

van Dessel, N. C., van der Wouden, J. C., Dekker, J., \& van der Horst, H. E. (2016). Clinical value of DSM IV and DSM 5 criteria for diagnosing the most prevalent somatoform disorders in patients with medically unexplained physical symptoms (MUPS). Journal of Psychosomatic Research, 82, 4-10.

van Goozen, S. H., Fairchild, G., Snoek, H., \& Harold, G. T. (2007). The evidence for a neurobiological model of childhood antisocial behavior. Psychological Bulletin, 133(1), 149-182.

Vesterling, C., \& Koglin, U. (2020). The relationship between attachment and somatoform symptoms in children and adolescents: A systematic review and meta-analysis. Journal of Psychosomatic Research, 130, 109932.

Waller, E., Scheidt, C. E., \& Hartmann, A. (2004). Attachment representations and illness behavior in somatoform disorders. Journal of Nervous and Mental Disease, 192, 200-209.

Wright, B., \& Edginton, E. (2016). Evidence-Based Parenting Interventions to Promote Secure Attachment: Findings From a Systematic Review and Meta-Analysis. Global pediatric health, 3, $2333794 X 16661888$.

Zeman, J., \& Shipman, K. (1996). Children's expression of negative affect: Reasons and methods. Developmental Psychology, 32(5), 842-849.

Zeman, J., Shipman, K., \& Suveg, C. (2002). Anger and sadness regulation: Predictions to internalizing and externalizing symptoms in children. Journal of clinical child and adolescent psychology: the official journal for the Society of Clinical Child and Adolescent Psychology, American Psychological Association, Division, 53(31), 393-398.

Zimmer-Gembeck, M. J., Webb, H. J., Pepping, C. A., Swan, K., Merlo, O., Skinner, E. A., Avdagic, E., \& Dunbar, M. (2017). Review: Is parent-child attachment a correlate of children's emotion regulation and coping? International Journal of Behavioral Development, 41(1), 74-93.

Publisher's Note Springer Nature remains neutral with regard to jurisdictional claims in published maps and institutional affiliations. 